\title{
Exposure times for colour discrimination in the parafoveal field: a new procedure to detect subtle visual dysfunction in multiple sclerosis patients
}

\author{
ROBERTA MENABUE,* PAOLO NICHELli,* SIlVIA BELlEI $\dagger$ \\ From the Clinica Neurologica* and the Clinica Oculistica, $\dagger$ Universita' di Modena, Modena, Italy
}

SUMMARY A new procedure to test colour discrimination in the parafoveal field is described. This method was used on 25 healthy controls and 25 subjects having a definite clinical or laboratorysupported diagnosis of multiple sclerosis, with or without a previous history of optic neuritis. The test proved to be sensitive in detecting visual dysfunction even in some patients in whom the standard technique of pattern-reversal evoked potential recordings yielded a normal result.

The diagnosis of multiple sclerosis is still clinical and depends on the demonstration of objective signs of lesions at two or more distinct sites in the white matter of the central nervous system in patients with a compatible history and in whom there is no satisfactory alternative explanation. ${ }^{1}$

The visual system is particularly vulnerable to demyelination in the course of multiple sclerosis. The incidence of optic neuropathy has approached $100 \%$ in the reported necropsy series, ${ }^{2}$ even in absence of any visual complaint during life. ${ }^{3}$ The likelihood of subclinical optic neuropathy is therefore high in multiple sclerosis patients and the ability to detect it may help to improve diagnostic accuracy.

Many different procedures can reveal subtle defects in the function of the optic nerve even in patients whose visual acuity and standard perimetry are normal. The most sensitive techniques, among the psychophysical ones, are those examining temporal resolution of visual stimuli, that is double light-flash discrimination ${ }^{45}$ and flicker fusion thresholds, ${ }^{6-8}$ delay in visual perception ${ }^{910}$ and colour discrimination. ${ }^{11-14}$

In this paper we describe a procedure which evaluates colour discrimination in the parafoveal field and utilises an experimental apparatus often found in neuropsychological laboratories.

Address for reprint requests: Dr P Nichelli, Clinica Neurologica, Via del Pozzo, 71, I-41100 Modena, Italy.

Received 24 May 1985 and in revised form 6 August 1985. Accepted 8 August 1985

\section{Material and methods}

\section{Apparatus}

A four channel tachistoscope (Gerbrands Model T4A) was employed to test patients and normal controls. The apparatus consisted of a four-field exposure cabinet supplied wi special chrome plated mirrors, which allow the presentation of stimuli either simultaneously or according to a fixeg sequence. Each field is lit by two 4 watt flourescent lamps whose intensity can be adjusted by means of a lamp drive by approximately $1 \log$ unit per field. The lamps are turnect on by a series of six timers and by a logic interface, which allows time intervals to be set to the nearest millisecond and provides the desired sequence of field exposures.

\section{Procedure}

Subjects were tested in a semi-darkened room and were first asked to sit with their eyes closed for five minutes. In this $\overrightarrow{\overrightarrow{0}}$ manner the same baseline viewing conditions were estab- 3 lished for all subjects. Each eye was tested separately. Patients sat in front of the tachistoscope and rested their face on a binocular viewer-mask, through which they could view the inside of the exposure cabinet. Spectacles were worn if appropriate, and the eye not being tested was occluded.

Before the exposure thresholds being examined, subjects $\bar{\partial}$ were asked to adjust the luminance of a red rectangle so that it appeared the same as that of an adjacent green rectangle, $\delta$ whose luminance was set at $2 \cdot 73 \mathrm{~cd} / \mathrm{m}^{2}$. For this purpose two channels of the tachistoscope were used, one for the red 0 and one for the green rectangle. The two rectangles were juxtaposed on the vertical meridian. Each of them subtended a visual angle of $10^{\circ}$ horizontal and $6^{\circ} 37^{\prime}$ vertical.

In order to evaluate exposure thresholds, eight red dots, $N$ each subtending a 23'36" visual angle, were then presented o on a green background, one at a time, at increasing exposure $\mathrm{N}$ durations. Not to provide any cue from an increase of lumi- N nance, for each red dot a green background was prepared 
with a black hole that was perfectly collimated with the dot. In this way, by simultaneously presenting the stimulus and the background, the red dot occluded the background. The luminance of dots and background was the same previously set by the subject himself for the two rectangles, so that dot detection could not be helped by cues other than colour contrast. In this way the characteristics of eight retinal sites were examined in each eye of every subject. All these sites were $2^{\prime \prime}$ eccentric: two of them were on the horizontal meridian, one in the upper and one in the lower field, and four were at $45^{\prime \prime}$ orientation to the horizontal meridian in each quadrant. Stimuli were presented to one or to the other eye according to a random sequence, which was repeated in all of the subjects.

Subjects were asked to fix the gap at the centre of a cross that was exposed on the third channel of the tachistoscope, and to show they had seen the brief exposure of a red dot by saying where it appeared with respect to the fixed centre. After a few warm-up trials, each dot was presented at increasing exposure times, starting from $10 \mathrm{~ms}$. Exposure times were incremented by steps of $2 \mathrm{~ms}$ to the limit of $100 \mathrm{~ms}$, by steps of $5 \mathrm{~ms}$ to the limit of $200 \mathrm{~ms}$, by steps of 10 $\mathrm{ms}$ to the limit of $1000 \mathrm{~ms}$ and by steps of $100 \mathrm{~ms}$ beyond this limit. Exposure thresholds were therefore obtained by the method of ascending limit for eight retinal sites in each eye.

\section{Controls}

The control group consisted of 25 healthy volunteers, 16 female and nine male, whose age ranged from 20 to 56 years with a mean of 34 years. None of them had had visual complaints, all of them denied ever having noticed problems in discriminating colours. All had 20/20 acuity (corrected as needed) and normal neuro-ophthalmologic examination.

Table Clinical data of the 25 multiple sclerosis patients
Tests of colour discrimination were not performed.

\section{Patients}

Twenty-five multiple sclerosis patients, 13 female and 12 male, ranging in age from 20 to 57 years with a mean of $35 \cdot 2$ years, were investigated in the Neurology Clinic of the Modena University. The disease was classified according to the criteria of Poser et al. ${ }^{15}$ On this basis 19 were labelled as clinically definite multiple sclerosis (CDMS), two as laboratory-supported definite multiple sclerosis (LSDMS) and four as clinically probable multiple sclerosis (CPMS). Eight patients reported they suffered visual symptoms consistent with acute demyelination of the optic nerve $(\mathrm{ON}+)$ and two of these eight patients had both eyes clinically affected. The remaining 17 patients had never complained of visual symptoms $(\mathrm{ON}-)$. Corrected visual acuity was $20 / 20$ in both eyes for 18 patients. Pattern-reversal visual evoked potentials (VEPs) was recorded in 16 patients. Exclusion of patients from VEP recording was mainly due to limited available facilities. Care was taken to avoid any systematic bias for patient selection. The latency of the major positive component of the transient VEPs was normal in five patients and delayed in the remaining 11. Clinical data are given in the table.

\section{Results}

Figure 1 shows means and standard deviations obtained by the control group for each of the eight retinal sites in the eyes.

A three way ANOVA, with two fixed criteria of classification (eyes and retinal sites) and one random

\begin{tabular}{|c|c|c|c|c|c|c|c|c|c|c|c|c|}
\hline $\begin{array}{l}\text { Age } \\
(y r)\end{array}$ & Sex & Diagn & $R O N$ & $L O N$ & $V R E$ & $V L E$ & $F R E$ & $F L E$ & $V E P R$ & $V E P L$ & $R E$ & $L E$ \\
\hline $\begin{array}{l}44 \\
39 \\
43 \\
25 \\
27 \\
22 \\
42 \\
40 \\
37 \\
20 \\
43 \\
45 \\
41 \\
37 \\
27 \\
57 \\
30 \\
50 \\
22 \\
34 \\
25 \\
38 \\
25 \\
46 \\
20\end{array}$ & $\begin{array}{l}\mathbf{M} \\
\mathbf{F} \\
\mathbf{M} \\
\mathbf{F} \\
\mathbf{F} \\
\mathbf{F} \\
\mathbf{M} \\
\mathbf{M} \\
\mathbf{M} \\
\mathbf{F} \\
\mathbf{M} \\
\mathbf{M} \\
\mathbf{F} \\
\mathbf{M} \\
\mathbf{M} \\
\mathbf{M} \\
\mathbf{F} \\
\mathbf{F} \\
\mathbf{F} \\
\mathbf{F} \\
\mathbf{M} \\
\mathbf{F} \\
\mathbf{M} \\
\mathbf{F} \\
\mathbf{F}\end{array}$ & $\begin{array}{l}\text { CDMS } \\
\text { CDMS } \\
\text { CDMS } \\
\text { CPMS } \\
\text { CDMS } \\
\text { CDMS } \\
\text { LSDMS } \\
\text { CDMS } \\
\text { CDMS } \\
\text { CPMS } \\
\text { CDMS } \\
\text { CDMS } \\
\text { CDMS } \\
\text { CDMS } \\
\text { LSDMS } \\
\text { CDMS } \\
\text { CPMS } \\
\text { CDMS } \\
\text { CDMS } \\
\text { CDMS } \\
\text { CPMS } \\
\text { CDMS } \\
\text { CDMS } \\
\text { CDMS } \\
\text { CDMS }\end{array}$ & $\begin{array}{l}- \\
+ \\
- \\
+ \\
- \\
- \\
- \\
- \\
- \\
- \\
- \\
- \\
- \\
- \\
- \\
+ \\
- \\
- \\
+ \\
-\end{array}$ & $\begin{array}{l}- \\
+ \\
- \\
- \\
- \\
- \\
+ \\
- \\
- \\
+ \\
+ \\
- \\
- \\
- \\
- \\
- \\
- \\
+ \\
- \\
- \\
-\end{array}$ & $\begin{array}{l}20 / 20 \\
10 / 20 \\
14 / 20 \\
20 / 20 \\
18 / 20 \\
20 / 20 \\
20 / 20 \\
20 / 20 \\
20 / 20 \\
20 / 20 \\
16 / 20 \\
20 / 20 \\
20 / 20 \\
20 / 20 \\
20 / 20 \\
20 / 20 \\
20 / 20 \\
20 / 20 \\
20 / 20 \\
10 / 20 \\
20 / 20 \\
14 / 20 \\
18 / 20 \\
16 / 20 \\
20 / 10\end{array}$ & $\begin{array}{l}20 / 20 \\
20 / 20 \\
18 / 20 \\
20 / 20 \\
20 / 20 \\
20 / 20 \\
20 / 20 \\
20 / 20 \\
20 / 20 \\
20 / 20 \\
16 / 20 \\
20 / 20 \\
20 / 20 \\
20 / 20 \\
20 / 20 \\
20 / 20 \\
20 / 20 \\
20 / 20 \\
20 / 20 \\
20 / 20 \\
20 / 20 \\
20 / 20 \\
20 / 20 \\
20 / 20 \\
20 / 20\end{array}$ & $\begin{array}{l}\text { tp } \\
\text { tp } \\
\text { tp } \\
n \\
n \\
n \\
n \\
\text { tp } \\
\text { tp } \\
n \\
n \\
n \\
n \\
n \\
n \\
n \\
n \\
n \\
n \\
\text { tp } \\
n \\
n \\
\text { tp } \\
\text { tp } \\
n\end{array}$ & $\begin{array}{l}\text { tp } \\
\text { tp } \\
\text { tp } \\
n \\
n \\
n \\
n \\
\text { tp } \\
n \\
n \\
\text { tp } \\
n \\
n \\
n \\
n \\
n \\
n \\
n \\
n \\
n \\
n \\
n \\
n \\
n \\
n\end{array}$ & $\begin{array}{l}> \\
\mathbf{n} \\
> \\
\mathbf{n} \\
\mathbf{n} \\
\mathbf{n}\end{array}$ & $\begin{array}{l}> \\
> \\
> \\
\mathbf{n} \\
\mathbf{n} \\
\mathbf{n}\end{array}$ & $\begin{array}{l}\mathbf{n} \\
> \\
> \\
\mathbf{n} \\
> \\
\mathbf{n} \\
\mathbf{n} \\
> \\
\mathbf{n} \\
\mathbf{n} \\
> \\
\mathbf{n} \\
\mathbf{n} \\
> \\
> \\
> \\
\mathbf{n} \\
> \\
\mathbf{n} \\
> \\
> \\
> \\
> \\
> \\
\mathbf{n}\end{array}$ & $\begin{array}{l}> \\
> \\
\mathbf{n} \\
\mathbf{n} \\
\mathbf{n} \\
\mathbf{n} \\
\mathbf{n} \\
> \\
\mathbf{n} \\
> \\
> \\
\mathbf{n} \\
\mathbf{n} \\
\mathbf{n} \\
> \\
> \\
\mathbf{n} \\
> \\
\mathbf{n} \\
> \\
> \\
> \\
\mathbf{n} \\
> \\
\mathbf{n}\end{array}$ \\
\hline
\end{tabular}

CDMS = Clinically definite multiple sclerosis; CPMS = Clinically probable multiple sclerosis; LSDMS = Laboratory-supported definite multiple sclerosis; RON = positive history of right optic neuropathy; LON = positive history of left optic neuropathy; VRE = visual acuity of the right eye; VLE = visual acuity of the left eye; FRE = fundoscopy of the right eye; FLE = fundoscopy of the left eye; tp = temporal pallor; $n=$ normal; VEPR = visual evoked potential recorded from the right eye; VEPL $=$ visual evoked potential recorded from the left eye; $\mathrm{RE}=$ exposure threshold of the right eye; $\mathrm{LE}=$ exposure threshold of the left eye; $>=$ defective performance. 


\section{RE}

39

$(27 \cdot 36)$

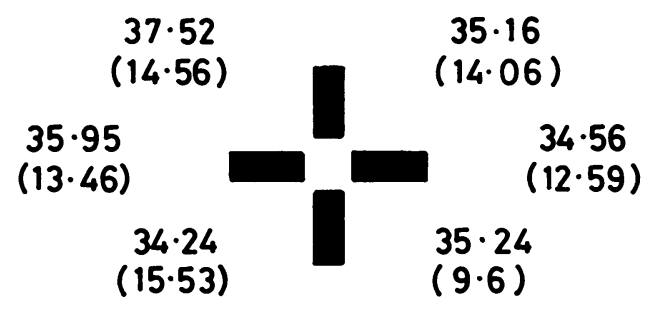

37.48

$(10.07)$
LE

$37 \cdot 80$

$(14 \cdot 08)$

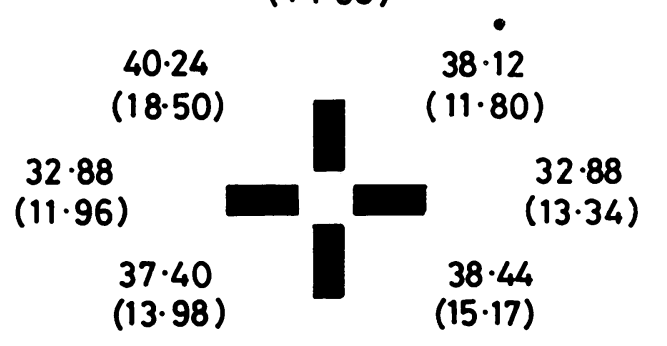

33.92

$(11 \cdot 67)$

Fig 1 Means (and standard deviations) of normal controls for each of the eight retinal sites tested in the right eye $(R E)$ and in the left eye ( $L E)$.

variable (subjects) was performed. The interaction between eyes and retinal sites was the only significant source of variability $(\mathrm{F}=4.6153 ; \mathrm{df}=7 ; \mathrm{p}<0.001)$. Careful investigation of the reasons behind this interaction disclosed an unexpected practice effect on the exposure thresholds: the last retinal sites tested showed an exposure threshold about $5 \mathrm{~ms}$ faster than those examined at the beginning of the session.

Tolerance limits including $99 \%$ of the normal population with a confidence level greater than $99.5 \%$ were calculated for each retinal site of the two eyes. The greatest and the lowest values so obtained were $61.84 \mathrm{~ms}$ and $54.48 \mathrm{~ms}$, respectively. For the convenience of diagnosis we took the former as the cutoff value between normal and defective performances. By this method only one control subject (a 56-year-old man who had never complained of visual problems) obtained defective exposure thresholds at more than one retinal site.

Another two control subjects obtained an exposure threshold slightly longer than the cut-off point $(70$ and $80 \mathrm{~ms}$ ) in one retinal site. We therefore decided to define the performance as defective only if exposure thresholds were found to be longer than the cut-off value at more than one retinal site.

Figure 2 shows the mean exposure thresholds for each eye in the control group and in $\mathrm{ON}+$ and $\mathrm{ON}-$ patients. From this figure it is evident that severely defective performances on the task of detecting briefly exposed dots were not limited to patients who had previously suffered visual symptoms, but also occurred with multiple sclerosis patients who had no positive history of optic neuritis. In fact only one out of the eight $\mathrm{ON}+$ patients was found to have exposure thresholds within the normal range in the affected eye, while five of them also showed abnormally long thresholds in the eye where they did not report any previous visual loss. Furthermore nine out

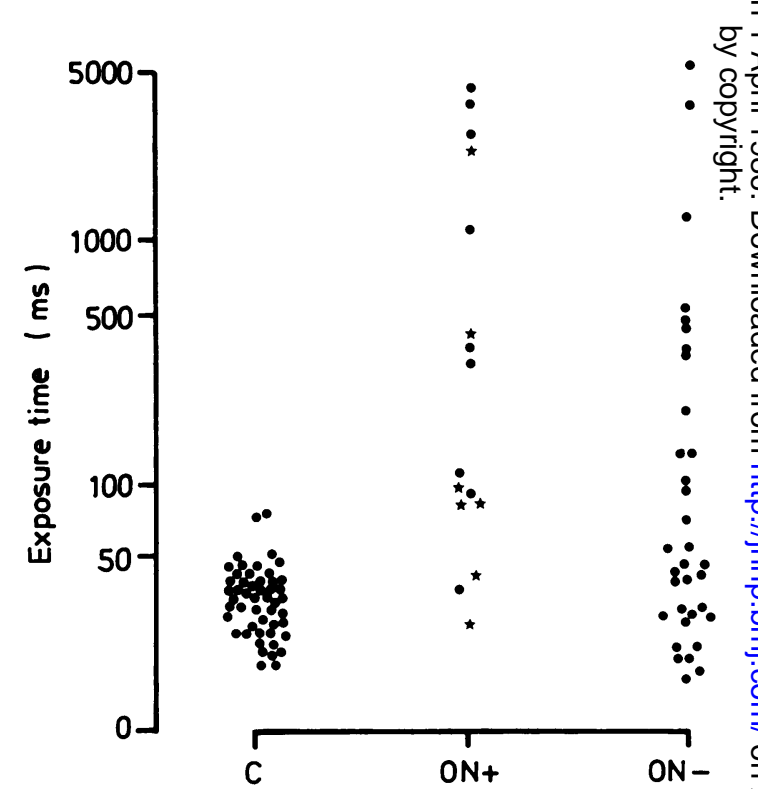

Fig 2 A comparison of mean exposure thresholds of the control group with the performance of patients with $(\mathrm{ON}+)$ and without $(\mathrm{ON}-)$ positive history of optic neuritis. Asterisks indicate performance of eyes at which $O N+$ patients did not report a positive history of optic neuritis (that is they reported visual symptoms only in the contralateral eye). 
of the $17 \mathrm{ON}$ - patients showed delayed thresholds and in five of these nine patients the delay was bilateral. Among the 20 eyes with abnormally delayed VEPs, only three eyes obtained exposure thresholds within the normal range. In contrast three out of the 12 eyes with normal VEPs showed a delayed exposure threshold (fig 3).

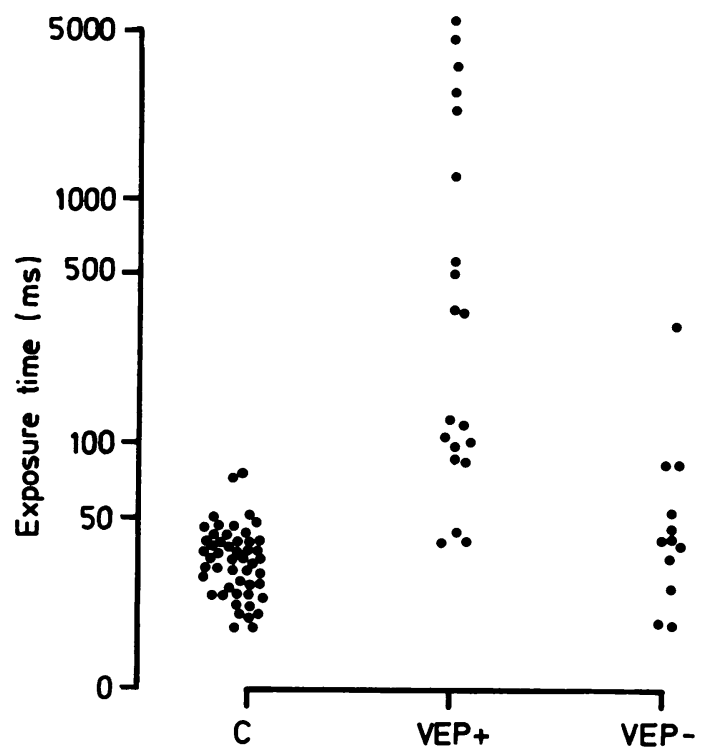

Fig 3 Mean exposure thresholds of controls plotted against those of patients where pattern-reversed VEPs were recorded. Eyes with increased latency of the major positive component $(V E P+)$ are considered separately from those whose VEPs were in the normal range (VEP-). Performances of $\mathrm{ON}+$ patients' eyes for which visual loss was not reported are represented with asterisks.

In one patient, whose exposure thresholds were delayed at three sites in one eye $(82,90$ and $220 \mathrm{~ms})$, VEPs were found to be normal under standard conditions, but when VEP recording was repeated after exposure to high luminance levels for 5 minutes, the latency of the major positive component turned out to have a biphasic shape. This effect had been previously reported in some multiple sclerosis patients with or without a positive history of optic neuropathy and interpreted ${ }^{16}$ as an indirect evidence of "islands" of demyelination showing a "visual-fatigue effect" which had been repeatedly revealed with lesions of the optic nerve. ${ }^{1718}$ It is likely that the localised delay of exposure thresholds in this patient reflected the same mechanism and that in such cases the evaluation of exposure thresholds might prove to be a more sensitive method than VEP recording under standard conditions.

\section{Discussion}

Early diagnosis is particularly important when multiple sclerosis is suspected. Indeed multiple sclerosis patients who initially show evidence of involvement at only one site of the central nervous system may not develop clinical signs of involvement at other sites until considerable time has elapsed, so that a definite diagnosis may be long delayed. Visual tests are likely to prove useful for early diagnosis since the visual system seems to be particularly sensitive to multiple sclerosis. $^{23}$

VEP recording has gained wide acceptance as a procedure to detect visual dysfunction in patients without a previous history of optic neuritis. The incidence of delayed VEP responses in patients with normal discs and no history of optic neuritis ranges from $38 \%$ to $94 \%,{ }^{19-27}$ depending on the criteria used for patients' inclusion and evaluating VEP abnormalities.

The main advantage of this procedure is that it is objective and so particularly useful with infants and for detecting organic pathology in patients with suspected psychogenic disorders. However, it is pointless to use complicated technical methods when a cheaper and simpler test adequately achieves for the same purpose. A body of evidence, based both on careful clinical observations and on the administration of specific testing procedures, ${ }^{11}{ }^{14}$ has accumulated over time to support the view that colour discrimination is one of the most sensitive techniques for investigating patients liable to have had optic neuritis. Moreover there are indications that for this purpose colour discrimination is as sensitive as VEP recording. ${ }^{28}$ Our method evaluates colour discrimination throughout the parafoveal visual field and therefore may be particulary useful when islands of demyelination impair vision only in discrete parts of the visual field.

The minimal exposure time for perceiving of a stimulus, which contrasted with the background only for colour, was found to be a sensitive method for testing visual dysfunctions in multiple sclerosis patients. This was probably not only due to their colour discrimination deficits, but also to the fact that exposure time was influenced by the delay in visual perception, which has been repeatedly claimed to be a peculiar visual defect in these patients. ${ }^{1029-31}$

There is no doubt that the procedure adopted requires good cooperation from patients, but this did not prove to be a problem in the majority of cases. The experimental apparatus used was not built specifically for the purpose of this test, a fact which made the procedure a little time consuming in some instances. A device purpose-built for this test would probably render it simpler and more easy to use in clinical practice. 
We are very grateful to the patients and control subjects who assisted in this study. We also thank Professor Pietro Faglioni and Professor Emilio Campos for their helpful advice and the Centro di Calcolo dell'Universita' di Modena for technical assistance.

\section{References}

${ }^{1}$ McDonald WI, Halliday AM. Diagnosis and classification of multiple sclerosis. Br Med Bull 1977;33:4-8.

${ }^{2}$ Lumsden CE. Neuropathy of multiple sclerosis. In: Vinken PJ, Bruyn CW, eds. Handbook of Clinical Neurology, vol.9. Amsterdam: Elsevier-North Holland 1970:234-47.

${ }^{3}$ Gartner S. Optic neuropathy in multiple sclerosis. Arch Ophthalmol 1953;50:718-26.

${ }^{4}$ Galvin RJ, Regan D, Heron JR. Impaired temporal resolution of vision after acute retro-bulbar neuritis. Brain 1976;99:255-68.

${ }^{5}$ Galvin RJ, Heron JR, Regan D. Subclinical optic neuropathy in multiple sclerosis. Arch Neurol 1977; 34:666-70.

${ }^{6}$ Titcombe AF, Willison BG. Flicker fusion in multiple sclerosis. J Neurol Neurosurg Psychiatry 1961;24:260-5.

${ }^{7}$ Parson OA, Miller PN. Flicker fusion thresholds in multiple sclerosis. Arch Neurol Psychiat 1972;77:323-50.

${ }^{8}$ Daley ML, Swank RL, Ellison CM. Flicker fusion thresholds in multiple sclerosis: a functional measure of neurological damage. Arch Neurol 1979;36:292-5.

${ }^{9}$ Heron JR, Regan D, Milner BA. Delay in visual perception in unilateral optic atrophy after retrobulbar neuritis. Brain 1974;97:69-78.

${ }^{10}$ Regan D, Milner BA, Heron JR. Delayed visual perception and delayed visual evoked potential in the spinal form of multiple sclerosis and in retrobular neuritis. Brain 1976;99:43-66.

${ }^{11}$ Steinmetz R, Kearns TP. H-R-R pseudoisocromatic plates: As a diagnostic aid in retrobular neuritis of multiple sclerosis. Am J Ophthalmol 1956;41:833-7.

${ }^{12} \mathrm{Marre} \mathrm{M}$. The investigation of acquired color deficiencies. In: Second Congress of the Internation Color Association, University of New York. July 2-6, 1973. London: Adam Hilger Publ 1973:99-135.

${ }^{13}$ Trusiewicz D. Fansworth 100 -hue test in diagnosis of ethambutol-induced damage to the optic nerve. $O p h$ thalmologica 1975;171:425-31.

${ }^{14}$ Griffin JF, Wray SH. Acquired color vision defects in retrobular neuritis. Am J Ophthalmol 1978;86:193-201.
${ }^{15}$ Poser CM, Paty DW, Scheinberg L, et al. New diagnostiz criteria for multiple sclerosis: guidelines for researc $\mathrm{P}$ protocols. Ann Neurol 1983;13:227-31.

${ }^{16}$ Campos EC, Bellei S, De Simone AA. Provocative test fofe early diagnosis of multiple sclerosis. Doc Ophtalme 1985; (in press).

${ }^{17}$ Enoch JM, Campos EC, Bedell HE. Visual resolution in patient exhibiting a visual fatigue or saturation-like effect: Probable multiple sclerosis. Arch Ophthalmat 1979;97:1976-8.

${ }^{18}$ Enoch JM, Campos EC, Greer M, Trobe J. Measurement: of visual resolution at high luminance levels in patient with possible demyelinating disease. Int Ophthalmot 1979;1:99-104.

${ }^{19}$ Halliday AM, McDonald WI, Mushin J. Delayed visua居 evoked response in optic neuritis. Lancet 1972;i:982-5-

${ }^{20}$ Asselman P, Chadwick DW, Marsden CD. Visual evoke $\$$ responses in the diagnosis and management of patienty suspected of multiple sclerosis. Brain 1975;98:261-82.

${ }^{21}$ Chain F, Mallecourt J, Leblanc M, Lhermitte F. Appor $\vec{P}$ de l'enregistrement des potentiels évoqués visuels au di $\overrightarrow{-}$ agnostic de la sclerose en plaques. Rev Neurol (Parisf్ 1977;133:81-8.

22 Zeese JA. Pattern visual evoked responses in multiple sclerosis. Arch Neurol 1977;34:314-6.

${ }^{23}$ Shahrokhi F, Chiappa KH, Young RR. Pattern shifț visual evoked responses. Arch Neurol 1978;35:65-71. +

${ }^{24}$ Bodis-Wollner I, Hendley CD, Mylin LH, Thornton Jै Visual evoked potentials and the visuogram in multiple sclerosis. Ann Neurol 1979;5:40-7.

${ }^{25}$ Kjaer M. Brain stem auditory and visual evoked potontials in multiple sclerosis. Acta Neurol Scand 1980? 62:14-9.

${ }^{26}$ Trojaborg W, Botter J, Saxtrup O. Evoked potentials immunoglobulin abnormalities in multiple scler@sิ $\mathrm{s}_{\infty}$ Neurology (NY) 1981;31:866-71.

${ }^{27}$ Kupersmith MJ, Nelson JI, Seiple WH, Carr RE, Weis PA. The 20/20 eye in multiple sclerosis. Neurolog gs (Cleveland) 1983;33:1015-20.

${ }^{28}$ Wray SH. Optic Neuritis. In: Lessel S, Van Dalen JTWō eds: Neuro-ophthalmology: A series of critical surveys of the international literature, vol 1. Amsterdam: Excerpt佂 medica 1980:18-30.

${ }^{29}$ Heron JR, Regan D, Milner BA. Delay in visual percep윽 tion in unilateral optic atrophy after retrobular neuritisBrain 1974;97:69-78.

${ }^{30}$ Rushton D. Use of the Pulfrich pendulum for detecting abnormal delay in the visual pathway in multiple sclero sis. Brain 1975;98:283-96.

${ }^{31}$ Regan D, Murray TJ, Silver R. Effect of body tem perature on visual evoked potential delay and visuaB. perception in multiple sclerosis. $J$ Neurol Neurosurgi Psychiatry 1977;40:1083-91. 